\title{
Communication Strategy of ICCS (Indonesian Community Care for Schizophrenia) in Giving Psycho-education to People with Schizophrenia and their Families
}

\section{Yuni Retnowati}

AKINDO (Indonesian Communication Academy)

\section{Abstract}

Indonesian Community Care for Schizophrenia (ICCS) is a community supporting people with schizophrenia and their families through psychoeducation services. These activities are offered via Facebook and face-to-face. This paper examines ICCS's strategy in using social media to deliver its psychoeducation services. A sample of people with schizophrenia and their families who had a role as caregiver was surveyed for their interpretation of ICCS's information posted on Facebook. The results showed that the messages were generally understood, and creatively communicated

Corresponding Author: Yuni Retnowati; email:

thegreatlecturer@gmail.com

Received: 09 April 2017

Accepted: 17 May 2017

Published: 12 June 2017

Publishing services provided by Knowledge E

(c) Yuni Retnowati. This article is distributed under the terms of the Creative Commons

Attribution License, which permits unrestricted use and redistribution provided that the original author and source are credited.

Selection and Peer-review under the responsibility of the ICoSaPS Conference Committee.

\section{G OPEN ACCESS} althought there was a lack of variety in the content and infrequent Facebook updates of the activities offered.

Keywords: communication strategy, psychoeducation, Schizophrenia

\section{Background}

Schizophrenia is a cerebral disorder resulting from a disproportionate level of dopamine, characterized by a loss of affective feeling or an emotional response and withdrawal from interpersonal relations, often followed by delusions and hallucinations. World Health Organization's data shows that more than 20 million people suffer from schizophrenia around the world. In Indonesia, the number of people with schizophrenia represents $10 \%$ of the population with around $20 \%$ in urban areas [7].

This disease usually begins to appear in early adulthood between the ages of 16 and 25. Such age is considered as the most productive in the young adult's development. People with schizophrenia can be productive if their families and support systems recognize the symptoms and receive therapy as early as possible to increase the probability of recovery. Besides intensive therapy provided by the mental health worker and a strong desire to recover, the family also plays an important role in the recovery. 
The combination of antipsychotic treatment and a psychosocial approach is an effective way of achieving healing and preventing a recurrence of a schizophrenic episode. Psychoeducation is one of the psychosocial therapies involving the schizophrenic, family and significant person in the patient's life. The goal of psychoeducation is to learn as much as possible about what schizophrenia is and how working knowledge on its treatment can prevent the recurrence.

Indonesian Community Care for Schizophrenia (ICCS) advocates for people with schizophrenia and their families. ICCS was founded by Bagus Utomo whose brother developed schizophrenic symptoms as early as 1995. There was not much information on the disorder at that time. In 1999-2000, when the Internet became widely available in Indonesia, Utomo started to research for information, which led him to family guide kit on schizophrenia. He then created a website about schizophrenia which has metamorphosed into the ICCS in Facebook group.

ICCS offers family treatment, education, and art publications for the sufferer's selfactualization virtually or even offline. They connect communities, governments, and other related institutions concerning mental health. This also bridges people to understand that the individuals with mental illness have the right to live equally to other normal ones do. The campaign seeks to remove the stigma of mental illness.

ICCS has 16000 members currently and continues to grow. They hold offline meetings regularly (in Jakarta once in two weeks, and once in three months in the local network). The local network is in Jakarta, Yogyakarta, Malang, Bandung, Surabaya, and Solo. The research was done in Yogyakarta.

In 2001 ICCS started a mailing list for care givers of people with schizophrenia to share their experience and knowledge. In 2009 they created a Facebook group that attracted thousands of members. ICCS aims to give accurate information about schizophrenia to the people to fight negative stigma toward people with this disorder. Education programs and routine meetings are conducted for sharing of experience between family and sources. These activities are offered online (in Facebook groups) and also in face-to-face through member meetings once a month.

The communication strategy supports the successful provision of psychoeducation to people with schizophrenia and their families. Proper communication planning and management can ensure that the right information about the prevalence of schizophrenia and available treatment options are widely distributed. This strategy should take its objective and communication media into account in order to reach its goal. The weaknesses of the ICCS communication strategy need to be identified so that the organization's gain can be targeted to new beneficiaries to further reduce stigma and to increase the recovery opportunity throughout the country. 


\subsection{Communication Strategy}

Communications strategy is an organization's way of planning and managing their message to achieve specific goals. Four important factors that must be considered in preparing a communications strategy, according to Effendy ([5]: 35):

1) Knowing the audience: Audience is active so not only mutual dealings occur between communicator and communicant but also they affect each other. There should be an active audience. This indicates that mutual dialogue occurs. All sides can affect each other.

2) Composing the message: Determine the theme and materials to raise attention. The first sign of effective communication is the attention being given to the messages delivered.

3) Determining the method

The message delivery consists of two aspects:

a. According to the manner of its implementation,

- Redundancy method: To persuade the audience by repeating messages

- Canalizing method: Persuading the audience to receive the message and then to gradually change their attitude and mindset.

b. According to the forms of its contents,

- Informative method: It is aimed at using the audiences' reason and minds and is conducted in the form of a statement, explanations, news, and so on.

- Persuasive method: Influencing the public by persuading. Audience excited either thoughts or feelings.

- Educative method: Giving an idea to the audience based on facts, opinions and experience that can be shown to be true deliberately, organized and planned for the aim of changing human behavior in the desired direction.

- Coercive method: Influencing audiences in the form of regulations, intimidation and usually support by a formidable force.

4) Selecting the communication medium

We can choose one medium or a combination of several media depending on the objectives to be achieved because the message and techniques used for each media has its disadvantages

\subsection{Community}

Community according to Kertajaya [9] is a group of people caring about each other more than they should, where a close personal relationship occurs in community 
between members because of their similar interest or values. Community as a group of people sharing similar interests created by four factors: (1) Communication and wishes to share, (2) Place agreed to meet, (3). Rituals and habits, (4). Influencer pioneering something to be followed by the members.

\subsection{Psychoeducation}

Psychoeducation is a form of education or training for a person with a psychiatric disorder that is aimed at treatment and rehabilitation. The goal of psychoeducation is to develop and to increase the patient's acceptance to the disease or disorder he/she experiences, the patient's participation in therapy, and the development of coping mechanism when the patients face the disease-related problems (Goldmanin \& Faridhosseini, 2010).

Generally, the Comprehensive of psychoeducation program, according to Kelliat [8], is as follows:

a. Didactic component: Health education, providing information on diseases and mental health system.

b. Skills component: Providing training on communication, conflict resolution, problem solving, assertiveness, behavior management and stress management.

c. Emotional component: Allowing ventilation and sharing feelings with emotional support. Mobilization of resources is required, specifically in the condition of crisis.

d. Social components: Increased use of formal and informal networking. The increased contact with the network of resources and existing support systems in the community will benefit families and clients.

\section{Method}

This descriptive study first conducted an in-depth overview of the communications strategy of ICCS in providing psychoeducation to people with schizophrenia and their family. This is complemented by a survey of 20 respondents: 4 persons with schizophrenia and 16 care givers from their respective families. Secondary data were obtained from interviews, field notes, photographs, personal documents or memos, and other official documents.

\section{Findings and Discussion}




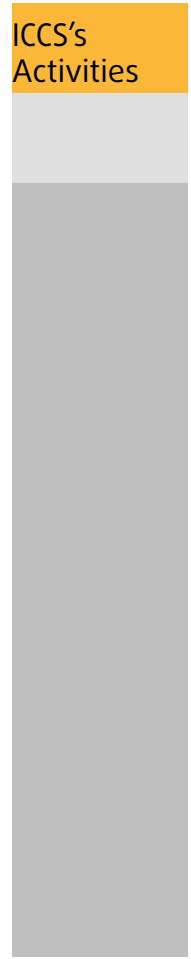

\begin{tabular}{|c|c|}
\hline $\begin{array}{l}\text { Online Activities Through Facebook } \\
\text { Group }\end{array}$ & $\begin{array}{l}\text { Offline Activities Through regular } \\
\text { Meeting }\end{array}$ \\
\hline $\begin{array}{l}\text { - Sharing knowledge about } \\
\text { mental health through } \\
\text { posting and translating } \\
\text { articles or information about } \\
\text { the topic. } \\
\text { - Supporting each other. It is } \\
\text { a catharsis medium for con- } \\
\text { sumers and caregivers to } \\
\text { share their burdens. } \\
\text { - Discussing family support, } \\
\text { coping mechanisms, } \\
\text { medication taken and issues } \\
\text { relating to mental disorder } \\
\text { treatment. Providing information about } \\
\text { seminars and workshops } \\
\text { locally, nationally, and } \\
\text { across the country. }\end{array}$ & $\begin{array}{l}\text { - Art therapy: painting, making } \\
\text { sculptures, making trinkets } \\
\text { - Yoga therapy to reduce emo- } \\
\text { tional problems } \\
\text { - Free counseling handled by a } \\
\text { psychiatrist } \\
\text { - Group therapy: peer sharing } \\
\text { group/FGD with caregivers, } \\
\text { sufferers, survivors, and a } \\
\text { peer support } 2 \text { times a month } \\
\text { - Psychoeducation for people } \\
\text { with Schizophrenia and their } \\
\text { families who take a role as } \\
\text { care giver and mental health } \\
\text { worker }\end{array}$ \\
\hline
\end{tabular}

TABLE 1: Online and offline activities of ICCS.

\subsection{Online and Offline Activities}

The table below shows the activities of online and offline ICCS

ICCS as a community has facilitated communication and shared experiences about schizophrenia. They provide a place to meet online in their Facebook Group and offline at the ICCS secretariat in Sawit Sari, Bunga Street Block I No 1 Sleman, Yogyakarta. They hold regular meetings with sharing events about schizophrenia, feast and end it with a door prize. Previous meetings were routinely held once a month. However, due to the demands placed on the board, who are all volunteers, regular meetings are now conducted every 2 to 3 months. The regular meeting agenda is determined by the board based on information and knowledge needed by members.

\subsection{Implementation of Psychoeducation}

Psychoeducation is intended for the families who live with schizophrenic, mental health professionals (psychologists, doctors, nurses, social workers etc.), the Mental Disorders Rehabilitation Board and members of ICCS. The material consists of: (1) being an effective tutor, (2) psychoeducation - concept of mental health, (3) schizophrenia disorders, (4) treatment of schizophrenia, (5) effective communication, (6) recurrence and schizophrenia crisis, (7) towards recovery, (8). empowerment and advocacy. The exercises are carried out by the board of ICCS with psychiatrists providing additional 
support. Psychoeducation is provided offline through face-to-face meetings, but according to most members of ICCS, psychoeducation is also offered effectively through the Facebook group in the form of posting information and articles about mental health and the management of schizophrenia.

\subsection{Communication Strategy in Psychoeducation}

Viewed from the method of implementation, the communicating strategy of the Facebook Group uses the repetition method, through repetition of message. The contents can be same message but different way of delivery. The content of the messages is delivered in the form of information about schizophrenia and the invitation to manage schizophrenia properly through medical treatment. Meanwhile psychoeducation conducted through face-to-face meetings uses canalizing method, focusing on changing attitudes and mindset in the messenger's intended direction. Psychoeducation materials are designed for that purpose.

Viewed from the form of message content, communication strategies through the Facebook Group use the informative method, provided in the form of an explanation. Meanwhile psychoeducation is conducted through face to face meetings; in addition to using informative techniques, it also uses educative media by providing facts, opinions and experiences considered as righteous based on a predetermined schedule in order to change the behavior so that the participants can deal with schizophrenia properly.

Psychoeducation reflects the characteristics of comprehensively involving didactic component by the distribution of information about mental health, skills component in the form of training, effective communication and the handling of recurrence. Psychoeducation also offers an emotional component in the form of peer sharing can be achieved through the Facebook group as well as through regular meetings, social component in the form of formal access to medical treatment and informal support through the Facebook group

\subsection{Advantages and Disadvantages of an ICCS Communication Strategy}

The advantages are easy to understand because communication materials have been adapted to the characteristics of the target audience. The term psychiatric simplified using the colloquial term that is easy to remember and understand. The delivering process is communicative in nature by using everyday language. Training materials are packed into something interesting and fun. In the training, participants are asked to do role play by applying knowledge in the form of attitudes and behavior. 
The disadvantage is that the psychoeducation material in the modules lack variety. Nonetheless, the communication strategy in delivering the content is appropriate because it offers two methods of communication. Meanwhile the Yogyakarta Facebook group updates less frequently; the ICCS Jakarta group is known for regular updates, posting materials about mental health and information events relating to mental health.

\section{Conclusion}

ICCS as a community has provided communication activities to share information, knowledge and experiences of schizophrenia and those affected by it. Psychoeducation activities are primarily intended to people with schizophrenia and their families, but follow-up support can also be provided by a mental health professional. Psychoeducation can be provided either online via the Facebook group or offline through a meeting scheduled with materials introduced in the form of modules.

The communication strategy should be tailored to the characteristics of the media and the recipient. The repetition method is suitable for the target audience's memory, while the canalizing method is the right way in the face to face approach. The informative and educative message content seems to be appropriate for psychoeducation. The advantages of the communication strategy are that the content of message is understandable and is communicated communicatively through a two-way communication. The disadvantages are the lack of variety in the educational materials offered in the standard modules and the update rarely made to the Yogyakarta branch's Facebook group.

\section{References}

[1] Adelobelle, Vanina. 2008. Corporate Community Management. http://www . vaninaadelobelle.com.

[2] Blake, Reed H., and Haroldsen, Edwin 0. 2003. Taxonomy of Communication Concept. Surabaya: Papyrus.

[3] Bordbar, Mohammad and Faridhosseini, Farhad. 2010. Psychoeducation for Bipolar Mood Disorder: Clinical Research, Treatment Approaches to Affective Disorders. Clinical Journal. Oxford: Oxford University Press.

[4] Davis, R. A., Flett, G. L., and Besser, A. 2002. Validation of a New Scale for Measuring Problematic Internet Use: Implications for Pre-Employment Screening. Cyberpsychology \& Behavior. 5 (4). pp. 342-343.

[5] Effendy, 0. U., 2008. Dynamics of Communication. Jakarta: Bumi Aksara. 
[6] Fajar Junaedi (ed). Communication 2.0: Theory and Implications. Yogyakarta: Aspikom Book Litera Publishers.

[7] Ismail, I. (2016). Worsening of myasthenia gravis after administration of injectable long-acting risperidone for treatment of schizophrenia: first case report. European Journal of Neurology, 23, 324.

[8] Kelliat, Budi Anna. 2005. Mental Health Nursing Process. Issue 2. Jakarta: ECG.

[9] Kertajaya, Hermawan. 2008. Meaning of the Community. Bandung: Gramedia Pustaka Indonesia.

[10] Utari, Prahastiwi. 2011. Social Media, New Media and Gender in the Whirlpool Communication Theory. 